\title{
EFFECT ON ACADEMIC PERFORMANCE BY LEARNING ONLINE THROUGH 3D ANATOMY ATLAS VERSUS 2D PRESENTATIONS
}

\author{
Ayesha Haque, Ruqqia Shafi*, Tayyaba Faisal**, Sajida Naseem***, Salma Ambreen, Aisha Rafi*** \\ Dental College, HITEC-IMS, Taxila/National University of Medical Sciences (NUMS) Pakistan, **Fazaia Medical College, Islamabad Pakistan, \\ ${ }^{* *}$ College of Physicians and Surgeons Pakistan, Islamabad Pakistan, ${ }^{* * * S h i f a ~ C o l l e g e ~ o f ~ M e d i c i n e, ~ I s l a m a b a d ~ P a k i s t a n ~}$
}

\begin{abstract}
Objective: To assess the effect of using a 3D atlas on academic performance and compare it with the use of power point presentations during online lectures for gross anatomy of the head.

Study Design: Comparative prospective study.

Place and Duration of Study: Department of Anatomy, Dental College, Heavy Industries Taxila Education City Institute of Medical Sciences, Taxila Pakistan, from Jun to Jul 2020.

Methodology: Forty-nine students from first year BDS were selected through nonprobability convenience sampling. They were assigned to two groups, A and B comprising of 25 and 24 students respectively. Group A was taught gross anatomy of head region via Zoom lectures employing a digital three-dimensional anatomy atlas application (Visual body, 2019). Group B was exposed to only two-dimensional pictures through presentations during their lectures. Ten teaching sessions were conducted with post session MCQ based assessments. One comprehensive assessment was conducted at the completion of the region. Results were compared for both groups.

Results: The mean scores for three of the post session assessment tests were higher for group A $(15.72 \pm 2.03,15.28 \pm 2.79$, $16.92 \pm 2.13)$ as compared to that of group B $(14.64 \pm 3.42,13.66 \pm 3.00,15.04 \pm 3.01)(p<0.05)$. Similarly, the mean score for comprehensive assessment for group A $(35.36 \pm 6.02)$ was also more than that of group B $(31.41 \pm 6.88)(p<0.05)$.

Conclusion: Three-dimensional viewing of structures led to better academic performance as compared to that of presentations with two dimensional pictures.
\end{abstract}

Keywords: Anatomy, 3D atlas, Online teaching, Three-dimensional view, Zoom.

How to Cite This Article: Haque A, Shafi R, Faisal T, Naseem S, Ambreen S, Rafi A. Effect on Academic Performance by Learning Online Through 3D Anatomy Atlas Versus 2D Presentations. Pak Armed Forces Med J 2021; 71(5): 1700-1704. doi: https://doi.org/10.51253/pafmj.v71i5.6963

This is an Open Access article distributed under the terms of the Creative Commons Attribution License (https://creativecommons.org/licenses/by-nc/4.0/), which permits unrestricted use, distribution, and reproduction in any medium, provided the original work is properly cited.

\section{INTRODUCTION}

Anatomy is one of the oldest disciplines of medicine and its sound understanding is considered essential for all health care professionals. ${ }^{1}$ This is because; recognition of anatomical relations is indispensable for successful execution of procedures and diagnosis in clinical settings. ${ }^{2}$ Being a fundamental discipline, Anatomy is taught as a major basic subject during the first and second years of Medicine (MBBS) and first year of dentistry education (BDS). However, a decline in the knowledge of anatomy has been reported frequently and physicians find their learning inadequate to apply in clinical settings. ${ }^{3}$ Many students consider it a complex subject with content overload and inability to remember anatomy knowledge in the long-term. This may be because conceptual understanding of anatomical structures also requires visualization and is a prerequisite for learning Anatomy. It has been seen that without exposure to special concept, learning of this

Correspondence: Dr Ayesha Haque, Associate Professor of Anatomy, Dental College, HITEC-IMS, Taxila Pakistan

Received: 27 Jun 2021; revision received: 30 Aug 2021; accepted: 01 Sep 2021 essential subject is challenging for students as well as clinicians. ${ }^{4}$ Traditionally cadaver dissection was considered adequate to develop this spatial orientation of structures. However recent curricular modifications, ethical considerations and lack of availability is making this once considered essential resource less feasible. 5,6

Currently main resources used to learn Anatomy include plastic models, lecture notes, power point presentations and textbooks. Although these resources are indispensable to gain knowledge, studies show that 3D online atlases could further aid to develop concepts of anatomical relations. ${ }^{7,8}$ Moreover, learners less adept in spatial interpretation find it difficult to learn solely from two-dimensional resources like text books ${ }^{4}$. Plastic models are a good option to study anatomy in 3D, however, good quality and detailed versions of these are expensive and have limited availability. Inadequate spatial comprehension may compromise retention of the knowledge of anatomy in senior students and clinicians. ${ }^{9}$ To address this, academicians has been focusing to improve existing methods to learn Anatomy. ${ }^{10}$ 
Furthermore, recent shift of medical education to online learning due to current COVID-19 pandemic has especially challenged teaching of anatomy. In absence of on campus available resources students have to rely on textbooks and online presentations. Under these circumstances, it is even more urgent to investigate and develop novel methodologies, which can enhance learning of this fundamental discipline.

In view of the aforementioned, a plan was devised to investigate and compare the academic scores of students who used 3D atlas and those learning through digital lectures during online zoom lectures. Results of this study may help to inform future decisions to incorporate 3D learning tools for anatomy.

\section{METHODOLOGY}

A comparative prospective study was carried out at the department of Anatomy, Dental College, HITEC-IMS, from June to July 2020.

Inclusion Criteria: All the first-year students enrolled in the Bachelor of Dental Surgery Cou-rse (BDS) were invited to participate in this study.

Exclusion Criteria: Any student with documented medical history of vertigo was excluded from the intervention.

Sample size was calculated by using open Epi calculator with confidence level at $95 \%$, power of test at $80 \%$ group 1 mean $\pm \mathrm{SD}=24.1 \pm 4.26$ and group 2 mean $\pm S D=30.96 \pm 6.23 .6$ Our sample size was 49 and students were assigned randomly into two groups: experimental group, A $(n=25)$ control group $B(n=24)$. The project was approved by the Institutional review board of Dental College, HITEC-IMS, Taxila (Ref No. Dental/HITEC/IRC/1/5). Research was conducted at the Department of Anatomy, from June to July 2020. All students gave their consent to be part of this research.

The research was conducted during the months of June and July when the campus was closed due to social distancing requirements of COVID-19. The syllabus included topics, which were to be covered during that module comprising of gross anatomy of the head region, brain, and cranial nerves. Learning objectives were covered in ten teaching sessions. Teaching was conducted through live classes on an online platform (Zoom). Content, tutors and assessment criteria remained the same for both groups. Each session lasted for approximately two hours. Topics were 3D human body atlas (Visual Body 2019), ${ }^{11}$ was used to show spatial view of the structures to the students in group A.
Instructors shared the screen with the students and manipulated the images to show multiple views and angles of structures (Figure). The 3D images were rotated as well as virtually dissected with adding and subtracting layers. Text information was also accessed through the application. For group B, live lectures were delivered using power point presentations and only 2D images of structures were shown to the students.

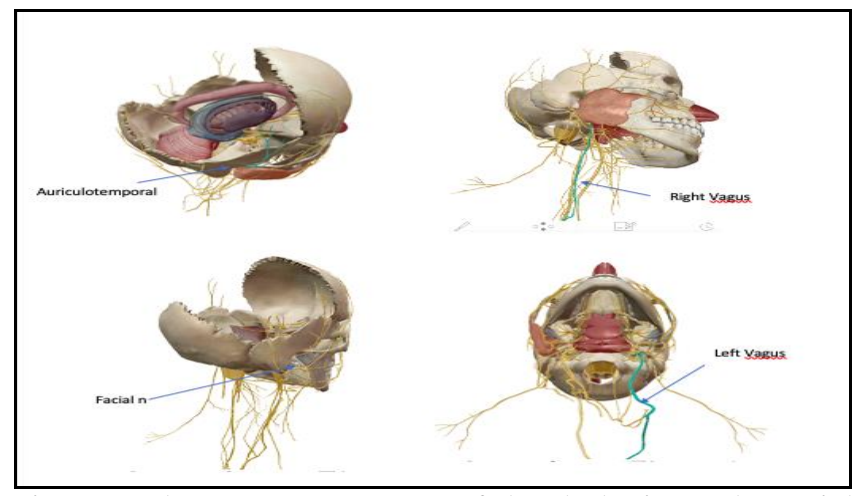

Figure: Select gross anatomy of head, brain and cranial nerves, Human Body atlas (Visible body 2019).

Both groups were assessed for their knowledge immediately after each session. These ten post-session assessments comprised of MCQ's. Both recall and cognition were assessed through the items. Google quiz was used as a platform to conduct these assessments. For both groups, the items were the same, but they were arranged in a random order for each participant. Three types of items were included in the exam. First type of questions required the students to name the structures and were included to examine the spatial memory through recall, the second type assessed the spatial knowledge through their reasoning capability and visuospatial cognition. Third type of questions were mixed assessing retention as well as deductive ability.

At the end of completion of all sessions a comprehensive MCQ based exam was conducted to assess long term retention and knowledge. MCQ's were included from learning objectives covered during all ten sessions. Mean scores for post session and comprehensive exams were compared for both groups A and B.

Demographic information was collected. Data was analysed through Microsoft Excel (2013). Mean and standard deviation were calculated. Independent samples, t-test was used to compare the academic performance of both groups. Statistical significance was considered at $p \leq 0.05$. 


\section{RESULTS}

A total of 49 students participated in this study. Males were $6(12 \%)$ and $43(88 \%)$ were females. All students were from first year BDS. The mean scores for post session assessments conducted at the end of each session were more in $3 \mathrm{D}$ exposed group A as compared to $2 \mathrm{D}$ presentation exposed group $\mathrm{B}$. In three out of a total of 10 post session assessments the mean scores were significantly higher in group A $(15.72 \pm 2.03$, $15.28 \pm 2.79,16.92 \pm 2.13$ ) when compared to mean scores of group B $(14.64 \pm 3.42,13.66 \pm 3.00,15.04 \pm$ 3.01) $(p<0.05)($ Table-I).

Similarly, the mean score for comprehensive assessment conducted at the end of region assessment was also statistically more for group A (35.36 \pm 6.02$)$ as compared to that of group B $(31.41 \pm 6.88)(p<0.05)$ (Table-II).

\begin{tabular}{|c|c|c|c|c|c|}
\hline \multirow{2}{*}{$\begin{array}{l}\text { Post } \\
\text { Session } \\
\text { Exams }\end{array}$} & & up A (n=25) & \multicolumn{2}{|c|}{ Group B $(n=24)$} & \multirow[b]{2}{*}{$\begin{array}{c}p- \\
\text { value }\end{array}$} \\
\hline & \multicolumn{4}{|c|}{$\begin{array}{l}\text { Mean Scores } \pm \text { SD } \\
(\text { Total } \text { marks }=20)\end{array}$} & \\
\hline 1. & & $4.28 \pm 3.16$ & & $33 \pm 2.77$ & 0.09 \\
\hline 2. & & $4.68 \pm 2.51$ & & $70 \pm 1.80$ & 0.12 \\
\hline 3. & & $5.72 \pm 2.03$ & & $4 \pm 3.01$ & 0.02 \\
\hline 4. & & $5.28 \pm 2.79$ & & $56 \pm 3.00$ & $0.05^{*}$ \\
\hline 5. & & $5.52 \pm 2.77$ & & $12 \pm 2.47$ & 0.06 \\
\hline 6. & & $4.52 \pm 2.38$ & & $45 \pm 3.01$ & 0.93 \\
\hline 7. & & $4.16 \pm 1.74$ & & $8 \pm 2.55$ & 0.90 \\
\hline 8. & & $6.92 \pm 2.13$ & & $4 \pm 3.01$ & 0.01 \\
\hline 9. & & $5.84 \pm 2.13$ & & $12 \pm 2.90$ & 0.33 \\
\hline 10 & & $5.76 \pm 3.11$ & & $33 \pm 2.21$ & 0.07 \\
\hline $\begin{array}{l}\text { Table-Il } \\
\text { group A } \\
\text { present }\end{array}$ & & $\begin{array}{l}\text { arison of cur } \\
\text { las exposed) } \\
\text { xposed). }\end{array}$ & & $\begin{array}{l}\text { exam scor } \\
\text { up B (2D p }\end{array}$ & betwee \\
\hline $\begin{array}{l}\text { Study } \\
\text { Groups }\end{array}$ & $\mathbf{n}$ & $\begin{array}{r}\text { Mean Sc } \\
\text { (Total mark }\end{array}$ & & $\begin{array}{c}\text { Std. } \\
\text { Deviation }\end{array}$ & $\begin{array}{c}p- \\
\text { value }\end{array}$ \\
\hline $\mathrm{A}$ & 25 & 35.36 & & 6.02 & \\
\hline $\mathrm{B}$ & 24 & 31.41 & & 6.88 & 0.03 \\
\hline
\end{tabular}

\section{DISCUSSION}

The is one of the first study in this region which compared the academic achievement of student groups exposed to 2D teaching methodology and 3D atlas application through online Zoom classes.

The results demonstrate that use of 3D anatomy atlas was beneficial and led to better academic performance of the participants as compared to those who were taught using 2D resources. The scores were higher in both post session assessments as well at the end of region assessment. This shows that learning and retention of anatomical knowledge was increased in short term as well as long-term.

These results are in concert with a number of previous studies with similar findings. For example study conducted by Faria et al, in São Paulo concluded that group exposed to 3D learning methods performed considerably well on test as compared to those who attended traditional lectures with $2 \mathrm{D}$ presentations (6.45 vs 4.35 on a scale of $0-10 ; p<0.05) .{ }^{12}$ In another study by Agbetoba et al used a methodology in which the students utilized a tool to draw 3D boxes on anatomical structures. They showed that $89.3 \%$ of students benefited from this software to understand better ${ }^{13}$. Although most of the studies agree that $3 \mathrm{D}$ resources help to develop spatial orientation a few researchers also contest these findings. Brewer et al concluded that academic performance did in improve in students who used a 3D brain model compared to those who utilized 2D images to learn $(23.5 \%$ and $22.3 \%$ respectively; $p=$ 0.95 ; scale $0-100 \%) .{ }^{14}$ Contrary to our results, Donnelly et al, reported better academic performance in students exposed to 2D methods as compared to 3D resources. ${ }^{15}$ Hassinger et al, had similar findings. ${ }^{16}$ However, these studies were regarded as relatively low quality in a metanalytical review by Triepels et al. ${ }^{17}$ Triepels et al, confirmed that most studies documented better understanding and academic performance by utilizing 3D modalities of learning.

This improvement of Anatomy understanding through 3D teaching methods could be attributed to a number of factors. For example, it has been shown that brain perceives 2D and 3D models differently. Anderson et al, compared electroencephalogram of students observing 2D and 3D structures and observed higher amplitude during observation of 3D structures. This led to their conclusion that learning through 3D facilitates recognition. This additional cue may have given the students an advantage in our study and other similar studies leading to better comprehension and retention of anatomical facts. 13,18

Another factor which might have played a role in better spatial conceptualization of structures in 3D is the cognitive load. This load has been shown to be lower while learning through 3D resources as compared to 2D learning. Roettl compared cognitive load among three different groups and documented that it was lowest under 3D conditions as compared to $2 \mathrm{D}$ and virtual learning groups. ${ }^{19}$ According to cognitive load theory intrinsic cognitive load is necessary effort that the individual puts in to concentrate and learn 
while extrinsic load is modulated by the instructional techniques ${ }^{20}$. For example, during traditional teaching visual overload is experienced when students are shown text and images on slides without adequate explanation to understand the information. To comprehend the observer must mentally reconstruct and rotate images to understand its spatial relations. This increases the extraneous cognitive load considerably decreasing the available space in working memory for intrinsic load. Adequate intrinsic load is necessary for learning and its replacement with extrinsic cognitive load will decrease academic performance. ${ }^{20}$ Availability of $3 \mathrm{D}$ rotatable images not only decreases cognitive load but also improves interpretation of anatomy in all dimensions. Literature shows that a decreasing cognitive load result in better performance. ${ }^{17}$ Less cognitive load may be one of the reasons for significantly better academic scores of students exposed to 3D anatomy in group A.

Another reason for higher academic achievement in 3D atlas exposed group (A) may be due to the novelty of this learning methodology. There is evidence that a new teaching method piques the interest and curiosity of the learner. ${ }^{21}$ Use of $3 \mathrm{D}$ atlas in this study may have generated more involvement and attentiveness in participants of group A as compared to those who were subjected to lectures with routine $2 \mathrm{D}$ images.

With advancement of medical informatics, limitations of cadaver-based learning and decrease in teaching time, computer-based 3D resources can provide an alternative, which is feasible, fosters learning and is effective. In recent years there has been a focus on development of resources which allows opportunity to visualize structures and dissect them virtually. ${ }^{22} \mathrm{Al}-$ though many anatomists still support learning through cadaver dissection, associated problems with it are a major concern. ${ }^{6}$ Moreover, the flexibility and cost efficiency of online learning through 3D resources is well documented with positive feedback from the students. 22 The students can visualize, and toggle various structures and the applications allow them to get explanations of clinically relevant anatomy instantly. Although the tactile sensations associated with live dissection are missing during use of this software application, it is interactive, allows students freedom to choose views, and provides autonomy to add or remove layers of structures offering virtual dissection experience (Figure).

The anatomy teaching in Pakistan has been predominantly traditional and on campus. Present crisis due to COVID-19 led to a sudden transition from campus to online teaching 23 . Building spatial concept through online teaching was a challenge especially for a subject like anatomy. Our study shows that use of 3D atlas can be a feasible addition to existing learning methods and can address some of the challenges presented due to lack of on campus resources. It has also shown that live online platforms like zoom can be used successfully to enhance spatial learning through use of 3D atlas applications for anatomy. The results also suggest that $3 \mathrm{D}$ atlas may enhance learning and use of this methodology may not only help to overcome difficulties presented due to present pandemic but may also pave the path for a sustainable system which could be incorporated in regular curriculum as an additional system to existing teaching methods.

\section{ACKNOWLEDGEMENTS}

We thank all students for participating in this research activity.

\section{CONCLUSION}

Use of 3D atlas application to teach students led to better academic performance as compared to those taught through presentations with 2D images. Zoom is an effective and feasible platform to use atlas application during online classes. This novel method could be an effective and sustainable teaching tool in the short term as well as long term.

\section{Conflict of Interest: None.}

\section{Authors' Contribution}

AH: Writing, concept, data analysis, RS: Writing, data analysis, TF: Evaluation, data analysis, SN: Evaluation, data analysis, SA: Evaluation, data analysis, AR: Critical evaluation, data analysis.

\section{REFERENCES}

1. Turney BW. Anatomy in a modern medical curriculum. Ann R Coll Surg Engl 2007; 89(2): 104-107.

2. Atlasi MA, Moravveji A, Nikzad H, Mehrabadi V, Naderian H. Learning styles and strategies preferences of Iranian medical students in gross anatomy courses and their correlations with gender. Anat Cell Biol 2017; 50(4): 255-260.

3. Fillmore EP, Brokaw JJ, Kochhar K,Nalin PM. Understanding the current anatomical competence landscape: Comparing perceptions of program directors, residents, and fourth-year medical students. Anat Sci Educ 2016; 9(4): 307-318.

1. 4.Cheung CC, Bridges SM, Tipoe GL. Why is anatomy difficult to learn? the implications for undergraduate medical curricula. Anat Sci Educ 2021; 1(1): doi: 10.1002.

4. Trelease RB. From chalkboard, slides, and paper to e-learning: How computing technologies have transformed anatomical sciences education. Anat Sci Educ 2016; 9(6): 583-602.

5. Qamar K, Ahmad A, Ashar A. Comparison of learning anatomy with cadaveric dissection and plastic models by medical students. Pak Armed Forces Med J 2014; 64(2): 219-224.

6. Triepels CPR, Smeets CFA, Notten KJB, Kruitwagen RFPM, Futterer JJ, Vergeldt TFM, et al. Does three-dimensional anatomy improve student understanding?. Clin Anat 2020; 33(1): 25-33. 


\section{D Anatomy Atlas Versus 2D Presentations}

7. Singh A, Min AK. Digital lectures for learning gross anatomy: a study of their efficacy. Korean J Med Educ 2017; 29(1): 27-32.

8. Nabil NM, Al-Mously N, Al Wathnani S, Abduldaiem A, Al-Issa $\mathrm{H}$. Medical students perception on anatomy knowledge relevance and retention during clerkship. J Contemp Med Educ 2014; 2(3): 147-151.

9. Park S, Kim Y, Park S, Shin JA. The impacts of three-dimensional anatomical atlas on learning anatomy. Anat Cell Biol 2019; 52(1): 76-81.

10. Human anatomy atlas. Visible Body [Internet]. Available from: http://www.visiblebody.com/ [Accessed on July 25, 2021].

11. de Faria JW, Teixeira MJ, de Moura Sousa Júnior L, Otoch JP, Figueiredo EG. Virtual and stereoscopic anatomy: when virtual reality meets medical education. J Neuros 2016; 125(5): 11051111.

12. Agbetoba A, Luong A, Siow JK, Senior B, Callejas C, Szczygielski $\mathrm{K}$, et al. Educational utility of advanced three-dimensional virtual imaging in evaluating the anatomical configuration of the frontal recess. Int Forum Allergy Rhinol 2017; 7(2): 143-148.

13. Brewer DN, Wilson TD, Eagleson R, de Ribaupierre S. Evaluation of neuroanatomical training using a 3D visual reality model. Stud Health Technol Inform 2012; 173(2): 85-91.

14. Donnelly L, Patten D, White P, Finn G. Virtual human dissector as a learning tool for studying cross-sectional anatomy. Med Teach 2009; 31(6): 553-555.
15. Hassinger JP, Dozois EJ, Holubar SD, Camp JC, Farley DR, Fidler $\mathrm{JL}$, et al. Virtual pelvic anatomy simulator: a pilot study of usability and perceived effectiveness. J Surg Res 2010; 161(1): 23-27.

16. Triepels CPR, Smeets CFA, Notten KJB, Kruitwagen RFPM, Futterer JJ, Vergeldt TFM, et al. Does three-dimensional anatomy improve student understanding. Clin Anat 2020; 33(1): 25-33.

17. Anderson SJ, Jamniczky HA, Krigolson OE, Coderre SP, Hecker KG. Quantifying two-dimensional and three-dimensional stereoscopic learning in anatomy using electroencephalography. NPJ Sci Learn 2019; 4(1): 10-15.

18. Roettl J, Terlutter R. The same video game in 2D, 3D or virtual reality-How does technology impact game evaluation and brand placements? PLoS One 2018; 13(7): e0200724.

19. Young JQ, Van Merrienboer J, Durning S, Ten Cate O. Cognitive Load Theory: Implications for medical education: AMEE Guide No. 86, Med Teach 2014; 36(5): 371-384.

20. Nawaz A. E-Learning experiences of HEIs in advanced states, developing countries and Pakistan. Universal J Educ General Studies 2012; 1(5): 72-83.

21. McNulty JA, Sonntag B, Sinacore JM. Evaluation of computeraided instruction in a gross anatomy course: a six-year study. Anat Sci Educ 2009; 2(1): 2-8.

22. Farooq F, Rathore FA, Mansoor SN. Challenges of Online Medical Education in Pakistan During COVID-19 Pandemic. J Coll Physicians Surg Pak 2020; 30(6): 67-69. 